\title{
A CATEGORIA TÓPICO NO PORTUGUÊS DE ANGOLA ${ }^{1}$ THE TOPIC CATEGORY IN ANGOLAN PORTUGUESE
}

\author{
Eduardo Ferreira dos Santos*
}

\begin{abstract}
Resumo: Nosso artigo tem como objetivo a apresentação de uma tipologia preliminar, baseados em estudos recentes sobre o português vernacular brasileiro (PVB), para a categoria tópico no português de Angola (PA). A partir das considerações de Zubizarreta (1997) para essa categoria discursiva, fazemos um levantamento da tipologia para o tópico presente em Araújo (2009), focalizando o PVB e que nos serviu de base para a comparação e delimitação dessa categoria no PA. Estudos como de Araújo (2009) e Galves (1998) apontam para a diferença entre a realização do tópico no português europeu (PE) e no português brasileiro (PB). Desse modo, buscamos uma tipologia preliminar para a categoria tópico no PA e suas aproximações com o PB. Os dados do PA que apresentamos baseiam-se nos dados presentes no Anexo de Santos (2010), apoiado no trabalho de Chavagne (2005).
\end{abstract}

Palavras chave: tópico; português de Angola; português vernacular brasileiro.

\footnotetext{
Doutorando da Faculdade de Filosofia, Letras e Ciências Humanas/USP. Bolsista CNPq.

1 Este trabalho resume o estudo sobre o tópico no português de Angola apresentado na dissertação de mestrado de Santos (2010). O autor agradece os comentários e sugestões dos pareceristas e deixa claro que os problemas que persistirem são de sua responsabilidade.
} 
SANTOS, E. F. A categoria tópico no português de Angola

\section{Introdução}

Neste artigo, apresentamos um estudo sobre a categoria tópico no português de Angola. Ao estudarmos essa categoria, estamos diante de um fenômeno de interface sintático/discursivo.

Estudos como de Araújo (2009) e Pontes (1987) apontam para a diferença entre a realização do tópico no português europeu (daqui em diante PE) e no português brasileiro (daqui em diante $\mathrm{PB}$ ). Merece atenção, portanto, mostrar como essa categoria é realizada no português de Angola (daqui em diante PA) e sua aproximação e/ou distanciamento do PE e do PB.

O artigo está estruturado da seguinte forma: na seção (1), discorremos sobre o conceito de tópico que utilizamos em nosso trabalho; na seção (2), apresentamos uma tipologia de tópico do tópico para o PB/PVB; na seção (3), apontamos as construções de tópicos presente em nosso corpus para o PA; seguem-se as conclusões do trabalho e as referências bibliográficas.

\section{O Conceito de Tópico}

Seguindo Zubizarreta (1997: 10), "o tópico é o sujeito de um predicado proposicional", e assumimos "que a articulação tópico-comentário é representada em termos de predicação, em que o comentário é uma sentença aberta que predica sobre o tópico" (Quarezemin, 2005: 15).

Na topicalização, há a referência a termos em relação semântica, e não sintática, com a estrutura actancial do predicado. Nas línguas, caracteriza-se pela extraposição para o início do enunciado de um termo - tópico -, com o restante do enunciado funcionando como comentário. A estrutura de uma sentença que apresenta, portanto, o constituinte com função informacional de tópico seria: informação pressuposta (tópico) mais um comentário, como observamos em²:

(01) a. O meu pai, ele trabalha nos feriados

b. [Nos feriados $]_{i}$, o meu pai trabalha

2 Quarezemin (2005: 15), dado (25), renumerado. 
A partir da suposição de que o tópico se encontra em posição A-barra (não argumental), ele é retomado na conexão com a posição aberta do comentário por um pronome - ele (01a) ou por uma categoria vazia (01b).

Assim como proposto para a categoria foco, Zubizarreta (1997) aponta que a interpretação do constituinte topicalizado pode ser representada por meio de sua estrutura de asserção (AS), conforme apontamos a partir do exemplo em:

(02) - E a banana? Quem descascou ela?

- A banana, a Maria descascou ela

Em (02), nota-se que Maria é o foco e a banana é o constituinte topicalizado da sentença e cuja AS se vê em:

(03) $\mathrm{A}_{1}$ : a banana/existe um $\mathrm{x}$, tal que $\mathrm{x}$ descascou $\mathrm{y}$

$\mathrm{A}_{2}$ : a banana $/ \mathrm{y} \mathrm{x}($ tal que $\mathrm{x}$ descascou $\mathrm{y})=$ Maria

Zubizarreta (1997) também propõe uma AS para a categoria sintáticodircursiva foco e chama a atenção para que não se confundam as suas identificações. A leitura das duas asserções em (03), representando a sentença que contém o tópico em (02), reforça essa colocação de Zubizarreta (1997: 10): [...] the topic can never be identified with the focus, because by definition, the topic is the subject of the propositional predicate and the focus is contained within that predicate.

\section{A Tipologia de Tópico no Português}

Seguindo a apresentação de Araújo (2009: 235-242) para o $\mathrm{PVB}^{3}$, apresentamos nessa seção, os tipos de sentenças com tópico para o PVB, que tomamos como direcionamento para a análise do tópico em PA.

\footnotetext{
3 Ao dizermos PVB, estamos nos referindo ao português não culto, chamado vernacular ver, entre outros, Oliveira (no prelo). O trabalho de Araújo (2009) privilegia o português falado em comunidades rurais com descendentes, em sua maioria, de escravos africanos que se fixaram em lugares remotos do interior do país. Assim, esse português afrobrasileiro está enquadrado na proposta de um PVB.
} 
SANTOS, E. F. A categoria tópico no português de Angola

\subsection{Topicalização de Objeto Direto (TOD)}

A topicalização de objeto direto (TOD) apresenta as seguintes características ${ }^{4}$ :

(i) um objeto deslocado à esquerda sem retomada clítica interna à oração:

(04) os pés de café trocô

(ii) o sintagma nominal que compõe este objeto geralmente é definido:

(05) A cachaça eu bebo todo dia, se eu todo dia eu fô lá na praça

(iii) não sofre restrições de ilha:

(06) ...esses criatório (porco, galinha) tamém eu tem muitos ano qu'eu num crio, né?

(iv) pode ocorrer em sentenças encaixadas:

(07) É mais perigoso, porque uma ... uma mulé ... grávida, pá ganhá neném em casa, eu acho muito perigo, porque lá no hospital ... já é ôta coisa, né?

\subsection{Tópico Pendente com Retomada}

O tópico pendente com retomada mantém uma relação semântica com a oração já que é retomado por um elemento interno à oração. Esse elemento pode ser um pronome forte ou clítico, uma expressão genérica, uma categoria vazia, um pronome demonstrativo, um numeral, dentre outros elementos.

Segundo Araújo (2009: 236), o tipo de retomada mais frequente em sua análise foi o da relação semântica continente/contido. Nessa retomada, o elemento topicalizado é um constituinte semanticamente mais amplo contendo o termo que o retoma internamente à oração, como vemos em ${ }^{5}$ :

4 Araújo (2009: 235), dados (6, 7, 8,10), respectivamente, renumerados. Ao nos referirmos aos dados de Araújo (2009) ao longo de nosso artigo, mantivemos a mesma proposta ortográfica da autora para a transcrição dos dados em seu trabalho.

5 Araújo (2009: 236), dado (13), renumerado. 
(08) Jogo, naquele tempo o futebol era mais efetivado ainda

O segundo tipo de retomada mais frequente é a retomada por pronome correferencial, isto é, pronomes que retomam pronomes com o mesmo índice referencial, conforme apontado $\mathrm{em}^{6}$ :

(09) $\underline{E u}$, meu nascimento é daqui mesmo, minha residênça é aqui

Araújo (2009:237) aponta que outro tipo de retomada mais atestado em sua análise é a feita por um elemento foneticamente nulo na posição de sujeito, como em ${ }^{7}$ :

(10) Aquela folha... os menino saía, ia caçá, né, aí O bateu aqui nos óio do cachorro

Para os outros tipos de retomada como a de quantificador, numeral, pronome pessoal na posição de objeto, retomada pronominal na posição de sujeito de encaixada e pronome indefinido, Araújo (2009: 237) aponta que houve uma realização inferior se comparada às realizações mostradas anteriormente ${ }^{8}$.

\subsection{Tópico Cópia}

Nas construções de tópico cópia, segundo Araújo (2009:237), a retomada interna à oração dá-se pela cópia do termo topicalizado, como vemos em:

(11) aí o tratô... a carreta empurro o tratô, e aí desceu de ladêra abaxo lixado...

6 Araújo (2009: 236), dado (15), renumerado.

7 Araújo (2009: 237), dado (16), renumerado.

8 Remetemos o leitor ao texto de Araújo (2009: 236-237) para o levantamento, em numero e percentagem, dos tipos de retomada nas construções de tópico pendente analisadas pela autora.

9 Araújo (2009: 238), dado (25), renumerado. 


\subsection{Tópico Sujeito}

Segundo Araújo (2009: 238), as construções de tópico sujeito caracterizamse por: (i) apresentar um sintagma preposicional, locativo ou adjunto, deslocado à esquerda sem a preposição, com comportamento similar a de sujeito da frase já que estabelece concordância com o verbo; (ii) não apresentar um pronome lembrete retomando o sintagma nominal anteposto; e (iii) não existir concordância verbal entre o verbo e o seu argumento externo, realizado em posição pós-verba ${ }^{10}$ :

(12) a. Os jogadores estão crescendo o cabelo

b. *Os jogadores está crescendo o cabelo

Araújo (2009:239) aponta que construções como (12a) são tópico sujeito porque é o tópico, e não o sujeito, que estabelece a concordância com o verbo, daí a agramaticalidade da sentença (12b). Araújo ainda aponta, a partir dos estudos de Galves (1998), que registros desse tipo de tópico não são encontrados em outras línguas românicas, tornando o PB sui generis em relação a esse tipo de tópico ${ }^{11}$.

\subsection{Tópico Pendente}

Para Araújo (2009: 240), nas construções de tópico pendente, o sintagma nominal que inicia a oração apresenta uma relação semântica com a frase, mas não apresenta uma relação sintática. Segundo a autora, não há um lugar interno na oração em que possa ocorrer a inserção desse constituinte topicalizado ${ }^{12}$ :

(13) médico sempre aí nas Serra, nesse Rapa mermo tem um posto...

${ }^{10}$ Araújo (2009: 238), dado (28a/b), renumerado.

${ }^{11}$ Remetemos o leitor à leitura de Araújo (2009: 239-240) para a divisão em grupos desse tipo de tópico a partir da seleção argumental dos verbos e sua relação com o Tópico Sujeito.

${ }^{12}$ Araújo (2009: 241), dado (40), renumerado. 


\subsection{Tópico com Cópia Pronominal ou Duplo Sujeito}

Segundo Araújo (2009:241), essa construção é caracterizada pelo deslocamento de um sintagma nominal para a posição de tópico sendo retomado por um pronome na posição de sujeito interna à oração, como é apontado $\mathrm{em}^{13}$ :

(14) E aqueles mele, eles é que faz arco

Araújo ratifica a posição de Galves (1998) sobre a posição obrigatória do pronome em posição de sujeito nessas construções ser justificada em função de o verbo ter perdido o traço de [pessoa] no português brasileiro, sendo necessário, portanto, a marcação desse traço no sujeito.

\subsection{Topicalização Selvagem}

Na topicalização selvagem, Araújo (2009:241 afirma que há um deslocamento de um PP, objeto indireto, complementos nominais, agente da passiva ou adjunto adverbial, desacompanhados de preposição, conforme vemos $\mathrm{em}^{14}$ :

(15) Futebol, a gente brincava, né...

(16) Ah, lacraia já fui mordido muitas vez

\subsection{Tópico Locativo}

Nesse tipo de construção, Araújo (2009: 242) aponta que o elemento topicalizado é um locativo e a preposição, em geral, acompanha o sintagma nominal deslocado, conforme apontamos em ${ }^{15}$ :

(17) nesse sertão nosso aqui tem cascavel demais

(18) pra Conquista ela sempre vai, mais eu...mas só

\footnotetext{
${ }^{13}$ Araújo (2009: 241), dado (43), renumerado.

${ }^{14}$ Araújo (2009: 242), dados (44) e (46), renumerados.

15 Araújo (2009: 242), dados (48) e (49), renumerados.
} 


\section{Construções de Tópico no PA - Abordagem Preliminar}

Nessa seção, apresentamos uma abordagem preliminar de uma tipologia da categoria tópico para o PA. Seguimos a tipologia proposta para o tópico no PVB, conforme descrito por Araújo (2009) e apontado na seção (2). O corpus que constituiu a análise a seguir encontra-se em Santos (2010) e baseia-se no conjunto de dados apresentados no trabalho de Chavagne (2005).

\subsection{Topicalização de Objeto Direto}

Conforme apontado por Araújo (2009: 235), a topicalização por objeto pode ser caracterizada por quatro características (cf. 2.1.), entre as quais podemos destacar, com exemplos do PA:

(19) Faculdade vai estudar em Luanda?

Em (19), temos um objeto - Faculdade - deslocado à esquerda sem retomada clítica interna à oração:

(19’) Faculdade vai estudá-la em Luanda?

(20) o relacionamento entre os teus colegas, tens visto assim à distância

Em (20), o constituinte topicalizado o relacionamento entre os teus colegas é realizado como um sintagma nominal definido.

Os exemplos em (19) e (20), do PA, estão de acordo com as características apontadas por Araújo (2009) para esse tipo de tópico. Segundo a autora, essa construção está presente em todas as modalidades do PB e atentamos ao fato dessa construção também ser apreendida no PA.

\subsection{Tópico Pendente}

Araújo (2009: 240) define esse tipo de tópico como uma relação apenas semântica do sintagma nominal com a frase, mas não uma relação sintática. Vejamos os exemplos do PA em: 
(21) Ainda sobre o basquetebol, qual é o teu fã na NBA?

(22) Para além do basquetebol, qual é a outra modalidade que vocês praticam aqui?

Em (21) e (22), os constituintes topicalizados ainda sobre o basquetebol e para além do basquetebol, exemplificam a exposição de Araújo (2009: 236) em apontar que o tipo de retomada para esse tipo de tópico é do âmbito semântico 'basquetebol', por exemplo, possui uma relação semântica direta com NBA e modalidade. Nota-se que essas duas construções do PA são introduzidas por marcas formais - ainda sobre e para além - caracterizando esse tipo de tópico como pendente.

\subsection{Tópico Pendente com Retomada}

Segundo Araújo (2009: 236), esse tipo de tópico mantém uma relação semântica com a oração já que é retomado por um elemento interno à oração, como vemos em:

(23) a Mandume e o Enga, como é que está a levar as duas coisas? ${ }^{16}$

Em (23), o tópico é representado pelos sintagmas determinantes a Mandume e $o$ Enga retomados ao final da sentença pelo constituinte as duas coisas.

\subsection{Tópico com Cópia Pronominal ou Duplo Sujeito}

Araújo (2009: 241) caracteriza esse tópico como o deslocamento de um sintagma nominal para a posição de tópico e a retomada pronominal deste sintagma na posição de sujeito interna à oração, como apontamos em:

(24) os professores eles declaram ou estão para declarar uma nova greve

${ }^{16}$ Mandume e Enga são instituições escolares de Angola. Essa informação é depreendida pelo contexto da interação entre os entrevistados. 
SANTOS, E. F. A categoria tópico no português de Angola

Em (24), o tópico da sentença é o sintagma determinante os professores, retomado pelo pronome eles que ocupa a posição de sujeito interna à oração do constituinte deslocado para a posição de tópico.

Galves (1998) demonstra que esse tipo de construção não se assemelha com alguma construção do $\mathrm{PE}^{17}$.

\subsection{Topicalização Selvagem}

Segundo Araújo (2009: 241), na topicalização selvagem há o deslocamento de um PP, objeto indireto, complemento nominal, agente da passiva e adjunto adverbial, todos sem a preposição, conforme vemos em:

(25) E futebol tem algum fã no futebol?

(26) O Jordan as pessoas gostam por uma certa particularidade

Em (25) e (26), notamos que os constituintes futebol e Jordan na posição de tópico, não estão regidos pela preposição, embora tenham sido deslocados de posições internas às orações que exigiriam um sintagma preposicional, como vemos em (26'):

(26') Do Jordan as pessoas gostam por uma certa particularidade

Para Brito, Duarte e Matos (2003), que trabalham com o PE, esse tipo de tópico ocorre apenas quando há deslocamento de um sintagma preposicional, objeto indireto, sem a preposição. O dado em (25), contudo, mostra que o deslocamento para a periferia esquerda deu-se com um sintagma preposicional não requerido pelo verbo, aproximando da classificação proposta por Araújo (2009).

\subsection{Tópico Locativo}

Araújo (2009: 242) diferencia o tópico locativo da topicalização selvagem, devido ao fato de que no tópico locativo, o sintagma nominal é acompanhado da preposição, como apontamos em:

${ }^{17}$ Galves (1998:21-22) define esse tipo de tópico como 'Tópico com Pronome Lembrete'. 
(27) no Lubango o mês de agosto tem sido quente

(28) Em Luanda, onde mora?

Em (27) e (28), temos dois exemplos de constituintes topicalizados - Lubango e Luanda - funcionando como locativos e acompanhados de suas preposições.

\section{Conclusão}

A partir da tipologia de tópico para o português proposta em nosso trabalho, especificamente para o PVB, verificamos que o nosso corpus para o PA atestou seis tipos de realizações para essa categoria: (i) Topicalização de Objeto Direto; (ii) Tópico Pendente; (iii) Tópico Pendente com Retomada; (iv) Tópico com Cópia Pronominal ou Duplo Sujeito; (v) Topicalização Selvagem; (vi) Tópico Locativo.

Uma abordagem preliminar da categoria tópico no PA aponta para a realização de dois tipos de tópicos não atestados no PE, mas presente no PVB, como a Topicalização Selvagem - para sintagmas preposicionados que não sejam somente objetos indiretos - e o Tópico com Cópia Pronominal ou Duplo Sujeito. A realização desses tipos de tópicos pode evidenciar uma aproximação do PA com o PVB, e consequentemente com o $\mathrm{PB}$, e abrir espaços para estudos mais aprofundados do português em Angola concomitante com as diferentes línguas africanas presentes e faladas nesse país. Evidencia-se, também, a urgência de estudos comparativos entre o PA e o PB e PE.

\section{Referências}

ARAÚJO, E. As construções de tópico. In: D. Lucchesi.; A. Baxter.; I. Ribeiro. (orgs.). O português afro-brasileiro. Salvador: EDUFBA, 2009, p. 231-250.

CHAVAGNE, J-P. La langue portugaise d'Angola - etude dês écrits par rapport à la norma europénne du portugais. Thèse de doctorat - Université Lumiér. Lyon 2 , Faculte de Langues, Paris. Unpublished, 2005.

GALVES, C. Tópicos, sujeitos, pronomes e concordância no português brasileiro. In: Cadernos de Estudos Linguisticos. Campinas: Editora da Unicamp, n.34, 1998, p.19-31. 
SANTOS, E. F. A categoria tópico no português de Angola

OLIVEIRA, M. S. D. de. Fronted WH-Questions followed by QUE ( "THAT”) in portuguese spoken in Brazil (BP/BVP): the substratist and universalist theories complement each other. (no prelo).

QUAREZEMIN, S. A focalização do sujeito no português brasileiro. Dissertação de Mestrado, Universidade Federal de Santa Catarina, 2005.

SANTOS, E. F. dos. A periferia esquerda da sentença no português de Angola. Dissertação de mestrado. FFLCH/USP, 2010.

ZUBIZARRETA, M. L. Prosody, focus and word order. University of Southern Califórnia, Departamento f Linguistics, Los Angeles, CA, Manuscript, 1997.

\begin{abstract}
This article aims at presenting a preliminary typology, based on recent studies on Vernacular Brazilian Portuguese (VBP), to the topic category in the Angolan Portuguese (AP). From Zubizarreta's considerations (1997) on this category of discourse, the topic typology presented by Araújo (2009) was examined, focusing on VBP, and that served as a basis for comparison and delimitation of this category in AP. Studies as carried out by Araújo (2009) and Galves (1998) point at the difference between topic performance in European Portuguese (EP) and Brazilian Portuguese (BP). Therefore, a searched for a preliminary typology to the topic category in AP and its similarities with $B P$ was carried out. The AP data here presented are based on the data presented in Annexe of Santos (2010), supported by Chavagne's studies (2005).
\end{abstract}

Keywords: Topic; Angolan Portuguese; Brazilian Vernacular Portuguese. 